\title{
Conhecimento e Interesse em Economia
}

João Antonio de Paula

Marco Crocco

Hugo E. A. da Gama Cerqueira

Eduardo da Motta e Albuquerque

\author{
Cedeplar - Universidade Federal de Minas Gerais \\ Cedeplar - Universidade Federal de Minas Gerais \\ Cedeplar e FAFICH - Universidade Federal \\ de Minas Gerais \\ Cedeplar - Universidade Federal de Minas Gerais
}

\section{RESUMO}

O artigo argumenta em favor da necessidade de preservar o pluralismo em economia. Discute: i) a natureza do conhecimento e de sua produção; ii) as especificidades da produção do conhecimento em economia e os condicionamentos histórico-culturais do conhecimento; iii) as implicações da hegemonia de certa concepção de método em economia.

\section{PALAVRAS-CHAVE}

metodologia da economia, imperialismo econômico, pluralismo metodológico, formalização

ABSTRACT

The article argues the need to preserve the pluralism in economics. The article examines: i) the nature of the knowledge and of its production; ii) the specificity of the knowledge production in economics and the historical and cultural conditionings of the knowledge; iii) the implications of the hegemony of a certain methodological conception in economics.

KEY WORDS economic methodology, economic imperialism, methodological pluralism, formalism

JEL Classification

B40, B4I, B20. 


\section{INTRODUÇÃO: DE ONDE VEM TANTA ARROGÂNCIA?}

É sintomático de um certo momento de intolerância, ativa e amplamente referendada por certas instituiçóes, que este texto deva invocar, desde logo, o grande humanista renascentista Erasmo. Nascido em 1467, em Roterdã, Erasmo viveu num mundo conflagrado por uma tensão que se desdobrará no terror das guerras religiosas, na consolidação de um fosso intransponível e crescentemente aumentado, em que concepções de vida religiosa vão se transformar em partidos, em exércitos, em legiões que, mobilizando suas verdades e suas máquinas de guerra, não hesitaram nem ante a devastação extrema, nem ante a possibilidade do extermínio de multidóes. Contra isto, contra a barbárie da intolerância, Erasmo mobilizou uma mesma e incansável arma - a tolerância, a defesa da justa medida entre a liberdade e a fé, entre a liberdade e as instituições religiosas, entre a liberdade e a religião tornada aparato contra a exaltação fideísta de Lutero e o apego institucionalista de Roma. Erasmo é a radical confiança no humano, em sua capacidade de construir a paz e de alcançar a justiça pelo caminho indescartável da tolerância.

Hoje, invocar Erasmo é reconhecer que o momento tem algo do obscurantismo daqueles tempos em que a fogueira e a espada resolviam, de ambos os lados, as disputas teológico-filosóficas. E ao colocar assim a questão, isto é, buscar transcender as "razões" particulares de Roma e de Lutero em nome da tolerância, da convivência, Erasmo tornou-se um dos heróis decisivos da humanidade, um daqueles que jamais servirá a não ser à decisiva causa - a emancipação humana fundada na liberdade e na justiça.

Lembrar Erasmo hoje a propósito do pensamento econômico e da economia vigente é atestar a sua fulgurante atualidade. Lembrar Erasmo hoje, nestes dois campos, é explicitar a presença de uma intolerância que tanto significa submeter multidôes à miséria e ao embrutecimento, em nome do capital, quanto é a imposição de uma ordem intelectual que se quer exclusiva, monopólio de todo o saber e de toda a racionalidade.

No texto que se vai ler a marcha da argumentação será a seguinte: num primeiro momento, discute-se o que é conhecimento e como produzi-lo. 
Num segundo momento, busca-se entender as especificidades da produção do conhecimento em economia e os condicionamentos histórico-culturais a que está sujeita. Na seqüência, são discutidas as implicações e os limites de certa concepção metodológica que orienta a prática contemporânea da economia mainstream.

\section{AS CONDIÇÕES DE POSSIBILIDADE DO CONHECIMENTO}

Num arroubo que destoa quando comparado com outros campos do pensamento, o pensamento econômico dominante reivindica para si o monopólio do conhecimento verdadeiro, ser a matriz eficaz de todo o saber racional e relevante no relativo aos fatos econômicos, ser possuidor de um programa de pesquisa capaz de dar conta de tudo quanto postula.

O mainstream em economia acabou por se generalizar, transitando hegemonicamente para outros campos. Para a sociologia e a ciência política, foi fixado assim por Adam Przeworski:

"considero essa abordagem sob sua forma usual, e mesmo bru-
tal, de ênfase na maximização bem informada da utilidade
guiada pelo interesse próprio, com ajustamento instantâneo
ao equilibrio. Por essa razão, utilizo os termos 'individualismo
metodológico', 'abordagem da escolha racional' e 'economia
neoclássica' de modo intercambiável." (PRZEWORSKI,
1988, p. 6).

Se tem se imposto como abordagem dominante nestes campos é que o mainstream em economia tem a oferecer algo que, sobretudo para ciências sociais, acusadas de vaguidão conceitual e inoperacionalidade analítica, parece significar um instrumento metodológico poderoso. Sobretudo, com as novas possibilidades abertas com a teoria dos jogos, a abordagem da escolha racional em ciências sociais reivindica-se capaz de construir programa de pesquisa dinâmico e resolutivo, nos mesmos termos que os econo- 
mistas do mainstream vão elogiar seu arcabouço metodológico por sua capacidade de dar respostas aos problemas que eles mesmos colocam. ${ }^{1}$

Esta virtual hegemonia da abordagem neoclássica nos campos já citados só a custo disfarça a sua pretensão monopolista. $\mathrm{Na}$ fala de vários de seus cultores, o pluralismo, ma non troppo, é admitido apenas no quadro de uma larga e confortável hegemonia do mainstream. É o que se lê, por exemplo, em alguns dos depoimentos colhidos no livro organizado por Maria Rita Loureiro - 50 anos de ciência econômica no Brasil. (LOUREIRO, 1997).

Esta pretensão de exclusivismo tem a ancorá-la a legitimação desta mesma abordagem, decorrente do valor atribuído pelo "mercado" - leia-se instituições sancionadoras do pensamento econômico - aos economistas e seus produtos formados pela tradição teórica em tela. Isto é, o valor social do pensamento econômico é definido pelos grandes centros de pesquisa, ensino e de poder político e econômico dos países anglo-saxões, resultando daí, como disse Eleutério Prado que
"Entre os economistas, um doutor de Chicago vale mais do que um doutor de Illinois, principalmente, do que uma dou- tora da New School. Um economista ortodoxo vale mais do que um economista heterodoxo. Um simples doutor formado nos Estados Unidos vale mais do que um doutor criativo for- mado no Brasil." (PRADO, 2001, p. 5).

Se se pergunta qual o instrumento para aferir tal escala de valores um economista formado nesta mesma tradição dominante dirá que é o mercado; que é ele que estabelece o que vai ser valorizado. Contudo, esse é um dos casos típicos em que se deve lembrar a brutal franqueza de Humpty Dumpty:

1 Este transbordamento da abordagem neoclássica para outras ciências sociais, também chamado de "imperialismo econômico", é fartamente documentado no artigo de LAZEAR (2000). Os argumentos deste autor em defesa dos princípios neoclássicos serão discutidos adiante, na terceira seção. 


\section{"Quando uso uma palavra - disse Humpty Dumpty em tom escarninho - ela significa exatamente aquilo que en quero que signifique... nem mais nem menos. "A questão - pondera Alice - é saber se o senhor pode fazer as palavras dizerem coisas diferentes." "A questão - replicou Humpty Dumpty - é saber quem é que manda. É só isso." (CARROL, 1977, p. 196).}

Trata-se, aqui, da explicitação do sentido básico de toda dominação teórica no campo das ciências sociais: ela é indescartável de seus comprometimentos político-ideológicos. No caso, a hegemonia contemporânea da abordagem neowalrasiana ${ }^{2}$ não está condicionada à saúde e consistência de sua estrutura teórico-metodológica e de sua relevância heurística ou social, mas, sobretudo, por sua aderência e funcionalidade à dominação do capital nesta época neoliberal.

$\mathrm{Na}$ verdade, sabe-se hoje que há críticas importantes, formuladas por economistas insuspeitos de esquerdismo e de grande reconhecimento acadêmico - como Hayek e Georgescu-Roegen - que questionam aspectos importantes da teoria neowalrasiana sem que isto signifique qualquer alteração no ânimo arrogante de seus cultores. ${ }^{3}$ De qualquer modo, desde os anos 1970, já se sabe que não há como

2 Seguindo autores como SCREPANTI \& ZAMAGNI (1993) e PRADO (2001), designamos de "abordagem neowalrasiana" a vertente atualmente dominante da economia neoclássica. Nos anos 1950, esta abordagem encontrou sua formulação canônica no modelo de Arrow e Debreu e, ao longo das décadas seguintes, tornou-se a estrutura básica para desenvolvimentos teóricos (estendendo-se inclusive à macroeconomia) e aplicados (a partir da difusão dos modelos de equilíbrio geral computável) no interior do campo neoclássico. Isto não significa desconhecer a existência de novos modelos que extrapolam os limites desta abordagem, apoiando-se nos desenvolvimentos em teoria dos jogos, teoria da complexidade e outras técnicas. Apesar disso, "look anywhere except at the most abstractly theoretical journals, and general equilibrium still characterizes the actual practice of economics. General equilibrium models have become ubiquitous in such important areas as trade theory and environmental economics, and are continuing to spread (...) An on-line search for publications on 'general equilibrium' turns up more than a thousand citations per year, with no evidence of declining interest in the subject." (ACKERMAN, 2002, p. 126).

3 Sobre as limitaçôes desta abordagem, ver também ACKERMAN (2002) e INGRAO \& ISRAEL (1990). 
"obter unicidade e estabilidade nos modelos de equilibrio geral (...). Tornara-se evidente que a promessa segundo a qual a teoria econômico-ortodoxa ficaria solidamente fundamentada na teoria do equilibrio geral não poderia ser cumprida (...). Desde então, a visão de mundo que representa, a qual fora construida nas uiltimas décadas do século XIX, entrou em processo de dissolução (...). A teoria dita neoclássica vai desaparecendo como visão de mundo, subsistindo apenas como técnica de modelagem ou fonte de elementos para a modelagem. Ainda que isto não esteja garantido para o futuro, o que passou a unificar a teoria econômica ortodoxa foi a aderência ao método de obtenção de resultados que parta de um problema de otimização. $\grave{A}$ medida que a formalização e a econometria vieram para o primeiro plano, a teoria econômica tornou-se autista." (PRADO, 2001, p. 17-18).

E, conclusivamente,

"como os economistas ortodoxos estão construindo uma homogeneidade interna e marcando diferenças em relação ao meio externo, não se importam ademais em parecer autistas. Eles estão estruturando um colégio invisivel de iniciados, cuja segregação interna se dá em tempos da competência nessas práticas de formalização matemática e econométrica." (PRADO, 2001, p. 19).

Seria ocioso continuar insistindo aqui em três pontos que já foram demoradamente marcados: 1) a hegemonia do pensamento neoclássico não decorre de sua especial acuidade teórica, da consistência ou relevância de seus resultados; 2) a agenda neoclássica, a maneira como as questóes são abordadas a partir deste campo teórico, traz consigo um enquadramento conservador e mistificador na medida em que naturaliza questóes que têm, sobretudo, dimensão histórico-político-social; 3) finalmente, reconheça-se que a crise dos fundamentos teóricos do pensamento neoclássico nem obrigou-a a recuo ou redução de sua proverbial arrogância, nem impediu-a de 
continuar a pleitear e impor uma hegemonia que se baseia numa virtual interdição de tudo quanto não se lhe submeta.

Invoque-se agora duas questões da ordem da fundamentação do conhecimento: uma primeira questão é a relativa à pretensão do pensamento neoclássico de ter o monopólio da racionalidade, interditando aquelas vertentes não-instrumentais da razão adotadas por outras abordagens. A outra questão diz respeito às condiçóes capazes de garantir o desenvolvimento do processo de conhecimento.

\subsection{As Matrizes da Racionalidade Moderna}

Acostumamo-nos a pensar na racionalidade moderna como tendo apenas um único e decisivo ramo - aquele que remete nos séculos XVI, XVII e XVIII, aos nomes de Galileu, Descartes, Newton, que tem seqüência nos séculos XVIII e XIX com Condorcet, Laplace, Comte, ao positivismo em geral e à explosão científica do século XX. Trata-se, como se sabe, de trajetória de extraordinário êxito, sobretudo pelo que trouxe ao desenvolvimento da ciência e da técnica. Mas, tem mais que isto a seu crédito. É que esta tradição filosófica e cultural veio libertar a humanidade: "uma das mais profundas revoluções intelectuais, e mesmo espirituais, que a bumanidade já conbeceu, conquista decisiva do espirito por si próprio, vitória decisiva na estrada dura e árdua que leva o homem à liberdade espiritual, à liberdade da razão e da verdade." (KOYRÉ, 1986, p. 11).

O caminho das ciências, da razão instrumental, se tem dimensão problemática - denunciada pela crise ambiental, por exemplo -, não pode significar invalidação de seus contributos decisivos, sob pena de regressismo obscurantista. Contudo, esta não é, nunca foi, nem por um momento - apesar do acerto geral da tese de Max Weber sobre a vitória da racionalidade instrumental, sobre a instauração do "mundo desencantado" - a única matriz da racionalidade moderna. E, mais apropriadamente, deve-se falar mesmo "polifonia da modernidade", mais que numa monologia reducionista. (PAULA, 1997). 
Na verdade, nos núcleos básicos de sentido das palavras racionalidade, razão, há uma ambivalência que tem um significado revelador. É que se a palavra razão, na sua acepção latina, remete a ratio - e, neste sentido, às idéias de contar, calcular, medir como se vê no livro razão de contabilidade -, em sua acepção grega, como logos, evoca os sentidos de ligar, reunir, pensar... isto é, uma outra e complementar dimensão da palavra razão. (LALLANDE, 1953).

Se é assim, tomar o sentido da palavra razão em apenas um dos seus pelo menos dois sentidos básicos é falsificar a questão, é empobrecê-la. E, de fato, é pelo menos como duplicidade que se põe a trajetória da racionalidade moderna. Se há a corrente hegemônica, aquela que presidirá os grandes desenvolvimentos técnico-científicos da modernidade, há uma outra matriz da racionalidade moderna - tão racional quanto a outra, porque aqui também trata-se de articular a theoria como pressuposto ontológico de todo agir, de toda a praxis, de toda a ação moral, que tem que informar, que deve balizar, a poièsis, a produção material. ${ }^{4}$

A racionalidade moderna tem, é preciso reconhecer, uma outra matriz, diferente e mesmo conflitante com a já referida, matriz que remete aos nomes de Montaigne, Pascal, Vico, Spinoza, Rousseau, Goethe, e cujo sentido geral foi ressaltado por Gerd Bornheim (1993), como constituindo um contraponto necessário ao predomínio daquela outra racionalidade, na medida em que esta se põe sobretudo como não-manipulatória da natureza, como um contraponto necessário à exacerbação instrumental dominante. No centro desta outra matriz da racionalidade moderna estaria o reconhecimento do caráter essencialmente contraditório da realidade; a com-

4 Ou, como formulado por Arnaldo Drummond, "a ciência que o grego criou e Aristóteles sistematizou consiste, em sintese, na interdependência da Lógica, Ontologia Geral e Gnosiologia. Reunidos, formam a acepção ampla de Metafísica, expressa nas três formas básicas de saber que compreendem o dominio relacional do ser humano: consigo mesmo, através do pensar objetivamente; com o outro, através do agir intersubjetivo; e com o objeto, através do fazer, respectivamente - theoria, praxis e poièsis." (DRUMMOND, 2002, p. 23). 
preensão da interdependência constituinte dos processos naturais e sociais; a presença irredutível da alteridade, da irreversibilidade, da indeterminação, do acaso, do espanto como componentes do real; o reconhecimento do tempo e da história como dimensões contingentes.

Em alguns dos representantes desta outra racionalidade há explícito ânimo crítico com relação aos construtores da racionalidade hegemônica - Vico quer a sua obra como crítica ao cartesianismo; Goethe se quer crítico tanto da teoria quanto da metodologia da teoria das cores de Newton. Duas figuras destacam-se, neste sentido, pela posição particularmente decisiva e ambivalente que terão no relativo às duas matrizes da racionalidade. Há Kant, que buscou em Rousseau um antídoto contra a revolução empirista de Hume. E há Marx, que Daniel Bensaid (1999, p. 284) vai surpreender numa admirável fusão de ciência alemã (romântica e antimanipulatória) e ciência inglesa (empirismo racionalista).

De tal modo que é como diálogo, tensão, complementaridade, contraponto, fecundação recíproca entre duas matrizes que a racionalidade moderna se desenvolveu. Assim, pretensões exclusivistas, reducionismos ou interdições neste campo são, claramente, estratégias regressivas, que só se sustentam pela imposição de poder discricionário.

\subsection{Elogio do Pluralismo}

Entre os seres vivos a diversidade de gens, espécies e ecossistemas é condição de sustentabilidade e de higidez. Ao contrário, a homogeneidade, a rarefação de variedades é sinal de comprometimento, é ameaça ao futuro. Quanto maior o patrimônio genético, quanto mais diferenciados os ambientes e seres, maiores as possibilidades de combinações enriquecedoras, da descoberta de novos usos, menores os riscos de definhamento pela combinação perversa de traços recessivos. Esta situação, amplamente reconhecida no campo dos estudos dos seres vivos e que se expressa com freqüência no contexto da questão ambiental a partir da idéia da importância da biodiversidade, tem incidência mais ampla, diz respeito ao campo mesmo da epistemologia e pode ser posta como a importância da diversidade das 
matrizes teórico-metodológicas como condições de desenvolvimento do conhecimento. Feyerabend viu assim a questão: "A proliferação de teorias é benéfica para a ciência, ao passo que a uniformidade lhe debilita o poder critico. A uniformidade, além disso, ameaça o livre desenvolvimento do individuo." (FEYERABEND, 1977, p. 45).

A história da ciência está repleta de exemplos em que o conhecimento foi produzido pela presença de uma atitude tolerante e aberta no sentido do acolhimento da multiplicidade de idéias. Veja-se o seguinte: "Feyerabend ha recordado que la concepción pitagórica de que a tierra se mueve fue abandonada por completo a partir de Aristóteles y volvió a revivir en Copérnico gracias a la tradición hermética, cuyo papel histórico todavía no ha sido explicado suficientemente." (FERNANDEZ BUEY, 1991, p. 101).

É também esta a motivação básica dos estudos de Francis Yates quando pretende nos mostrar os fundamentos herméticos, tipicamente pré-modernos, da grande revolução filosófico-cultural do Renascimento. Trata-se, na verdade, de reconhecer a presença da "ciência hermética", da magia e metafísica, na fecundação de obras decisivas para a modernidade como as de Giordano Bruno, John Dee, Bacon, Kepler, e, até mesmo, Newton. (YATES, 1991-1996). Isto é, a grande lição a se extrair da pesquisa de Francis Yates é o quanto de artificial e equívoco existe em certa imagem da modernidade, sobre seus fundamentos epistemológicos, quando se a vê como ruptura absoluta com um passado considerado como feito de trevas e ilusões. Na verdade, o processo de instauração da modernidade não fez tábula rasa de tudo quanto o antecedeu e é preciso reconhecer-se a relação entre o pré-moderno e o moderno como marcada por continuidade e ruptura, como situação dialética. Insista-se no ponto. A história da renovação espiritual representada pelo Renascimento é a história da importância da negação do estabelecido, é a história do papel decisivo que as idéias heréticas têm no desenvolvimento cultural. Veja-se o que diz Koyré:

"Desde los trabajos de Max Weber y de E. Troeltsch conocemos el papel jugado en la historia de las ideas, e incluso en la historia a secas, por los pequeños grupos sectarios protestantes. Fue ahi, en estos medios de 'fantasiosos' y de 'entusiastas', como 
se los denominaba durante la Reforma, entre los heréticos que vagaban de ciudad en ciudad, perseguidos cada vez con mayor dureza por las iglesias protestantes, donde seguia vivo el impulso de renovación espiritual que habia preparado y alimentado la Reforma." (KOYRÉ, 1981, p. 7).

E é também este mesmo espírito de renovação que Christopher Hill surpreende nas seitas protestantes na Inglaterra revolucionária do século XVII. Diz ele:

\begin{abstract}
"Nem devemos deixar de levar em consideração experiências que ligam a religião e a ciência, que, embora irreais para nós, eram tão conclusivas quanto experiências de laboratório para os contemporâneos. Richard Hakluyt foi levado à cosmografia pela leitura do Salmo 107. Descartes, Pascal e lorde Herbert de Chesbury tiveram visões, tanto quanto Gerrard Winstanley, George Fox e John Bunyan. Para todos esses homens, a experiência do coração era tão real quanto os dados dos sentidos.” (HILL, 1992, p. 399-400).
\end{abstract}

Trata-se, então, de reconhecer e extrair disto as conseqüências necessárias, que o lugar do poder não é, necessariamente, o lugar do conhecimento; que a produção do conhecimento pressupóe liberdade e autonomia; que a produção do conhecimento pressupõe diversidade de fontes e tradições teóricas, que é, enfim, todo o inverso das tendências contemporâneas dominantes no campo da economia que querem reduzir o campo à reiteração de uma mesma e problemática matriz.

Como disse Feyerabend, "o mundo, inclusive o mundo da ciência, é uma entidade complexa e dispersa, que não pode ser capturada por teorias e regras simples.” (FEYERABEND, 1994, p. 150). O corolário necessário desta última tese é que a ciência será tanto mais rica e capaz de desenvolver-se quando mais aberta estiver, quanto mais diversas foram as suas referências - as ciências sociais, o mundo, a vida são tão mais capazes de desenvolvimento quanto mais imersas na diversidade estiverem. A história do pensamento, a his- 
tória estão cheias de exemplos do papel decisivo que a diversidade, que a rica floração do diverso tem na preservação e expansão da vida espiritual.

\section{A PRODUÇÃO DO CONHECIMENTO EM ECONOMIA}

Nas ciências sociais, na economia em particular, a "ciência normal" é uma ilusão cuidadosamente construída. Na verdade, reina ali a ausência de paradigmas, de amplos e reconfortantes consensos. É que há, permanentemente, disputa de perspectivas conflitantes, que buscam explicar, a partir de métodos e conceitos não convergentes, os mesmos objetos.

No fundo desta realidade está o fato de que a economia, disse Parsons referindo-se à "economia clássica", mas que é tese geral - "não é só uma disciplina técnica, senão, além disto, uma ideologia." (PARSONS, 1967, p. 97). Isto é, que são inextricáveis do discurso da economia seja comprometimentos de classe, interesses particularistas, seja destinação ética, virtualidades normativas, mesmo quando escondidas sob a capa de uma pseudociência positiva.

Reconhecer isto, no entanto, não significa admitir a ausência de hegemonias, que elas se fazem e se expressam no largo domínio exercido por certas teorias no interior da comunidade de seus praticantes e receptores - escolas, veículos de divulgação, associações científicas e profissionais, instituições demandantes do campo de atuação das teorias, instituições financiadoras de pesquisa etc..

Estas teorias, hegemônicas por certo período, extraem sua validação de um conjunto de circunstâncias:

i) pela aparente capacidade de responderem aos desafios colocados pela realidade concreta;

ii) pela sintonia que apresentam com os interesses das classes dominantes; 
iii) pela capacidade que apresentam de se deixarem simplificar e padronizarem-se;

iv) pelo investimento massivo e permanente em instrumentos e práticas de sua reiteração e divulgação;

v) por seu auto-atribuído monopólio da virtude científica, que se manifesta pelo uso de certo instrumental, a formalização matemática, que assume aí o selo da autenticação científica por antonomasia.

A teoria hegemônica busca, permanentemente, apresentar-se como a única possibilidade de conhecimento racional, interditando, efetivamente, buscando desqualificar, desconhecendo tudo quanto não se alinhe aos seus supostos, métodos e conceitos.

O resultado desta versão contemporânea do Index da intolerância religiosa é um virtual empobrecimento teórico, tão mais obliterante quanto mais se lembre, como mostrou Feyerabend, que a história do desenvolvimento científico, em diversos campos e momentos, se fez pela rememoração, pela irrupção, pela redescoberta de certas teses e idéias, que em algum momento foram consideradas mortas, definitivamente ultrapassadas. Foi Popper quem disse que

"Cada vez mais candidatos ao PhD recebem um treino me-
ramente técnico, um treinamento em certas técnicas de
mensuração; eles não são iniciados na tradiçãa cientifica, na
tradição crítica da formulação de problemas, de serem testa-
dos e guiados antes pelos enigmas grandiosos e aparentemente
insolíveis do que pela solução de pequenos quebra-cabeças."

E ele o disse a propósito das ciências naturais, concluindo: "Se a maioria dos especialistas se limita a adotar uma atitude de 'mostrar serviço', será o fim da ciência tal como a conhecemos - da grande ciência." (POPPER, s.d., p. 46).

Não se quer aqui atribuir à economia lugar no mundo da grande ciência. Trata-se de sublinhar, como advertência, que a transformação da pesquisa em economia numa recorrente demonstração do poder mensurador de cer- 
tos métodos e modelos é um caminho certo para sua transformação num ramo secundário da matemática aplicada. Isto é, um exercício fútil e irrelevante do ponto de vista do conhecimento da realidade econômica, e que só se sustenta por seu papel ideológico.

Foi Popper, também, quem surpreendeu estes técnicos, estes especialistas, que, aparentemente cônscios das limitações de seus fazeres, traem orgulho e arrogância na medida em que proclamam esta "especialização" como necessária, como único e legítimo caminho e, na medida em que se desqualifica e se interdita tudo quanto não se subordine ao pensamento dominante, que tem, na verdade, pretensões de ser único.

Toda a questão, neste caso, é perguntar-se sobre quais seriam os elementos que questionariam uma certa hegemonia teórica. A resposta de Shackle é

$$
\begin{aligned}
& \text { "É quando se percebe repentinamente que o esquema é incon- } \\
& \text { sistente internamente ou falha na acomodação das observa- } \\
& \text { çôes ou não suporta os interesses da nossa própria porção da } \\
& \text { humanidade, que ele é atacado, destruido, reconstruido." } \\
& \text { (SHACKLE, 1991, p. 284). }
\end{aligned}
$$

No caso do pensamento econômico dominante, a nova ortodoxia neoclássica, é mais que patente que sua hegemonia não decorre de sua particular acurácia explicativa, de sua pertinência e realismo. Se se examinar com cuidado a "saúde" do edifício teórico neoclássico e, sobretudo, o resultado concreto das políticas decorrentes de seus princípios, ter-se-á um quadro que de nenhum modo pode autorizar a arrogância exibida por seus cultores.

Trata-se, aqui, neste sentido, de dizer que a hegemonia de uma certa corrente do pensamento econômico é parte de uma certa hegemonia políticocultural, a qual é sustentada por uma determinada dominação de classe, por uma certa configuração da luta de classes.

De tal modo que a crise de uma certa hegemonia teórica no campo da economia é sempre o resultado do questionamento sócio-político-econô- 
mico-cultural da hegemonia da classe dominante, questionamento este que, tendo seu centro na luta concreta entre as classes sociais, em suas determinações materiais, tem também dimensão especificamente cultural, filosófica, teórica. E aqui afirma-se a tese de Adorno sobre o horizonte necessário da prática emancipatória no mundo contemporâneo e que se traduz no duplo exercício de "resistir e contraditar".

\subsection{Epistéme ou Paradigma?}

Cassirer (2001, p. 338) lembrou-nos que a palavra epistéme remete às idéias de firmeza e estabilidade. É que a humanidade precisa de segurança, precisar afastar a confusão e a incerteza. Para mitigar estas afecções Descartes elaborou seu Discurso do método: "O método, método da dívida e das idéias claras, forma o bloco de que não se pode separar nada. E é o método, ou seja, o caminho, o único caminho capaz de nos libertar do erro e levar-nos ao conbecimento da verdade." (KOYRÉ, 1986, p. 22).

Afastar a confusão e a incerteza, eis o projeto cartesiano, como antes, Maquiavel, com sua teoria do estado, com a sua teoria política, buscou afastar o medo e a insegurança, buscou, com a consolidação da res pública, garantir a paz e a segurança num quadro de turbaçóes freqüentes, de lutas e disputas sangrentas. É ainda o medo, como foi observado por vários estudiosos, que vai motivar a teoria hobbesiana, de tal modo que o pensamento político dos séculos XVI e XVII, que a epistemologia cartesiana, no século XVII, são ecos de uma grande demanda de paz e segurança da Europa, atravessada pelas tensóes que se manifestaram com a Reforma, com a eclosão da modernidade, com os conflitos religiosos, com as disputas que levaram à Guerra dos Trinta Anos (1618-1648), às várias crises que marcam o século XVII. (LUBLINSKAYA, 1983).

É também sobre este período que vai se debruçar Michel Foucault em seu livro As palavras e as coisas, em que busca estabelecer a epistéme do que ele chama Idade Clássica, e que se confunde com a época moderna. Para Foucault, a Idade Clássica, que iria do século XVI ao XIX, seria marcada, do ponto de vista epistemológico, por três grandes epistémes. A do século 
XVI, cujo sentido básico é a centralidade da idéia de similitude, da analogia e da simpatia, como elementos de inteligibilidade. (FOUCAULT, s.d., p. 34). A epistéme dos séculos XVII e XVIII, que se expressaria, em três campos decisivos - na Filologia, na Biologia e na Economia Política, como Gramática Geral, História Natural e Análise da Riqueza. E a epistéme do século XIX, que, nos mesmos três campos, vai se pôr então como Sintaxe, Fisiologia e Análise da Distribuição, de um lado, e do outro lado como Fonética, Anatomia Comparada e Análise da Produção. (FOUCAULT, s.d., p. 281).

Interessa-se aqui pelo relativo à economia política. Foucault vai mostrar que o pensamento econômico do século XVI, como todos outros saberes, é pobre e pletórico, isto é, se faz pela acumulação de fatos, por uma interminável adição, cujo resultado final é sempre a incompletude. Diz Foucault "No século XVI, o pensamento econômico limita-se, ou quase se limita, ao problema dos preços e ao da substância monetária." (FOUCAULT, s.d., p. 223). E isto significa, naquele momento de ampla hegemonia do pensamento metalista, identidade absoluta entre os signos de riqueza e a riqueza mesma, já que não se afasta, é princípio absoluto, a tese da fungibilidade da moeda - "Para os 'economistas' do Renascimento, e até mesmo para Davanzatti, a aptidão da moeda para medir as mercadorias e a sua permutabilidade repousava no seu valor intrinseco." (FOUCAULT, s.d., p. 231).

No século XVII, e no XVIII, haverá uma mudança significativa na epistéme da economia, diz Foucault, com o pensamento mercantilista e, sobretudo, com a economia política clássica. Emerge uma nova problemática, uma nova maneira de conceber e de analisar os fenômenos econômicos. No centro desta revolução epistêmica está a emergência de um novo sentido de riqueza: "As relações entre riqueza e moeda estabelecem-se, pois, na circulação e na troca, e não já na 'preciosidade' do metal.” (FOUCAULT, s.d., p. 237). E, assim, a economia política vai se implantar pela constituição de um objeto que é, para Foucault, a análise da riqueza, isto é, a análise das trocas, a análise dos objetos de necessidade, a análise da circulação do comércio, a análise dos preços. (FOUCAULT, s.d., p. 281). 
Trata-se, neste sentido, de reconhecer as diferenças dos modos de apreensão dos problemas econômicos decorrentes de três momentos históricos distintos - o século XVI, em que a economia é um campo reflexivo ainda tributário da hegemonia da identidade entre os signos e a sua substância, em que o poder tem que ser sempre, e incontornavelmente, legitimado pela absoluta "verdade" de seus atos, em que a representação tem que ser capaz de convencimento e legitimidade incontestáveis, em que não há ainda lugar para a separação entre o poder e seu corpo físico, em que o corpo do rei é sagrado e o lugar efetivo do poder. (KANTOROWICZ, 1985). Neste sentido, a economia renascentista, ao absolutizar a substância fungível da riqueza, não está mais que replicando o sentido geral de uma época, de uma epistéme, que não pode representar senão a partir da presentificação dos seres, concretos e inumeráveis.

A grande ruptura que a economia vai experimentar, nos séculos XVII e XVIII, é a possibilidade de análise dos símbolos da riqueza, para além de sua fungibilidade. É isto que vai permitir o desenvolvimento da teoria do valor, da economia política, que terá com Smith e Ricardo sua culminância, exatamente na medida em que eles vão estabelecer a centralidade do discurso da economia política a partir da análise da produção e da distribuição. Diz Ricardo:

\begin{abstract}
"O principal problema da Economia Politica consiste em determinar as leis que regem esta distribuição; e embora esta ciência tenha feito grandes avanços com os escritos de Turgot, Stuart, Smith, Say, Sismondi e outros, eles proporcionaram muito poucos dados satisfatórios sobre a evolução natural da renda, lucros e salários." (RICARDO, 1978, p. 25).
\end{abstract}

De tal modo que nos séculos XVII - XVIII, para Foucault, vai se impor uma epistéme cujos termos básicos são:

valor $\rightarrow$ preço

troca $\rightarrow$ circulação e comércio

dinheiro $\rightarrow$ objetos de necessidade (penhor monetário), 
enquanto que no século XIX, a Economia Política vai ser epistemicamente articulada a partir de uma dupla determinação

análise da produção $\rightarrow$ análise da distribuição. ${ }^{5}$

Esta epistéme, que é sobretudo uma maneira de sintetizar o conjunto de interrogações sobre um certo objeto reflexivo, não significa, de forma alguma, homogeneidade de respostas às interrogações básicas sobre o objeto. Isto é, a existência de uma epistéme, o reconhecimento da existência de um campo reflexivo organizado por uma determinada maneira de olhar e interrogar o objeto, não deve ser entendido como significando o reconhecimento da existência de um paradigma, à moda de Thomas Kuhn. Na verdade, a história da economia política é a história da reiteração da inaplicabilidade do conceito de paradigma e, desde logo, por uma razão central. É que na economia política, o objeto é sempre objeto em disputa, que não oferece a paz do consenso, o reconforto da unanimidade.

Foucault viu a questão quando disse

"a economia apenas conhece um único segmento teórico, mas que é susceptivel simultaneamente de duas leituras feitas em sentido contrário. Uma analisa o valor a partir da troca dos objetos da necessidade, objetos úteis; a outra a partir da formação e do nascimento dos objetos, cuja permuta definirá em seguida o valor - a partir da prolixidade da natureza. Reconbece-se, entre estas duas leituras possiveis, um ponto de heresia que nos é familiar, o qual separa o que se denomina

5 As relações estabelecidas aqui (e as indicadas na página seguinte) utilizam a notação que está no texto citado de Foucault. Esta notação emprega sinais gráficos como setas, linhas pontilhadas e linhas cheias que buscam estabelecer contigüidades, semelhanças, pertencimentos conceituais. $\mathrm{O}$ propósito destes sinais não é o de indicar determinações absolutas e unívocas, mas o de indicar proximidades e correlações de nenhum modo unilaterais. Cremos que não será arbitrário dizer que os sinais gráficos no texto que se está lendo, as setas indicam pares conceituais contíguos onde o sentido da seta indica a sucessão lógica e genética das categorias: o conceito de preço, por exemplo, pressupóe a existência do conceito de valor e os dois conceitos pertencem a um mesmo campo conceitual. 


\section{"teoria psicológica" de Condillac, de Galiani, de Graslin, da teoria dos fisiocratas, com Quesnay e a sua escola." (FOUCAULT, s.d., p. 255).}

O ponto decisivo aqui é reconhecer que o mesmo objeto - a formação dos preços das mercadorias - pode ser explicado a partir de duas maneiras distintas, não necessariamente complementares, segundo alguns de seus cultores, e as duas maneiras de assim proceder não têm qualquer razão para duvidarem do acerto de suas teses. Isto é, não há qualquer razão forte para que abandonem suas teses, ou aceitem serem elas ilegítimas. Na história do pensamento econômico estas teorias que chamaremos objetivas e subjetivas do valor têm uma longa trajetória que poder-se-ia traçar assim:

\section{A - Teorias Subjetivas do Valor}

1. Utilitarismo $\rightarrow$ 2. Teoria Marginalista / Neoclássica $\rightarrow 3$. Teoria Neowalrasiana.

\section{B - Teorias Objetivas do Valor}

1. Fisiocracia $\rightarrow 2$. Economia Política Clássica $\rightarrow 3$. Teoria Marxista do Valor.

E daí que, como já foi observado com acerto antes, se não faz sentido e mesmo tem algo de nonsense alguém se proclamar um físico newtoniano no tratamento das questões adscritas à física clássica ou um biólogo reivindicar sua condição de pasteuriano, no campo da economia faz sentido e é informação relevante que alguém se reclame economista marxista, neowalrasiano, institucionalista, keynesiano etc.. É que não há lugar para paradigmas em economia. E a razão disto, independente do fato das ambigüidades do próprio conceito de paradigma, foi surpreendida por Kant em sua terceira antinomia da razão pura e por Marx quando disse que se a teoria das órbitas dos planetas, por exemplo, tivesse implicaçóes políticosociais, também ela, bem como todas as outras teorias sobre a realidade natural igualmente incidentes sobre a realidade social, seria objeto de disputas e contestações ideológicas. 
Para Kant, a pretensão de fundamentação de uma teoria pura, neutra, natural das realidades histórico-sociais esbarra numa antinomia intransponível, que é o fato do mundo histórico-social ter como móvel a liberdade: " $A$ causalidade segundo as leis da natureza não é a única de onde podem ser derivados os fenômenos do mundo no seu conjunto. Há ainda uma causalidade pela liberdade que é necessário admitir para explicar.” (KANT, 1985, p. 406).

Daí que se deve afastar por insubsistente as teses que buscam considerar os fenômenos histórico-sociais como fenômenos naturais, isto é, estáticos, imutáveis, agregáveis ao infinito como se sólidos minerais fossem. É só pela assunção de uma hipótese absurda - a de que os indivíduos são não diferenciados, imutáveis e dissociados (PRZEWORSKI, 1988, p. 7) - que o pensamento neowalrasiano pode estabelecer sua teorização, e assim buscar afirmar-se como paradigma em economia.

A antinomia explicitada por Kant, a irredutibilidade do mundo da liberdade a causações estáticas, é um obstáculo decisivo a qualquer pretensão de reducionismo naturalista, como é o caso exemplar da teoria econômica, tomada como teoria do equilíbrio geral. Neste caso, há muito fortes evidências da filiação desta teoria à mecânica estática, como se vê pela importante influência exercida sobre Walras por Louis Poinsot e seu livro Eléments de statique. (PAULA, 2002). Não é ocioso lembrar que aqui se está diante da influência de uma matriz da física clássica anterior aos desdobramentos decorrentes da segunda lei da termodinâmica e a abertura para a irreversibilidade, para a incerteza que ela traz. Louis Poinsot e Walras, que vai levar a estática para a economia, são tributários ainda do modelo newtoniano, da física determinística, ao contrário do que sugere Mirowsky, que quer ver na teoria neoclássica uma aplicação metafórica da física da termodinâmica. (PAULA, 2002, p. 143).

Trata-se aqui de, simplesmente, negar que haja no desenvolvimento do pensamento econômico, em qualquer de seus momentos, um paradigma aceito pelo conjunto da comunidade de seus praticantes. Na segunda metade do século XVIII, época do predomínio da teoria do valor trabalho, contestava-lhe a hegemonia o utilitarismo de Condillac-Bentham; neste nosso tempo de hegemonia neowalrasiana é um insuspeito Hayek quem diz 
"Tenho profundo sentimento de que o próprio conceito de equilibrio e os métodos que empregam na análise pura só tem um significado claro quando restritos à análise de uma única pessoa. (...) as proposiçôes tautológicas (equilibrio geral) da análise do equilibrio puro enquanto tais não são aplicáveis à explicação das relações sociais (...).” (HAYEK, 1997, p. 186187).

O justamente celebrado livro de Thomas Kuhn - A estrutura das revoluçôes cientificas - fez tal sucesso que é o caso de se pensar no acerto daquela frase que diz que o "sucesso é o resultado do conjunto de mal-entendidos que se produzem sobre um evento, uma pessoa." Deste modo, poder-se-ia dizer que a aparente simplicidade do conceito de paradigma induziu ao erro e mesmo bloqueou a compreensão de aspectos importantes do campo epistemológico. É o caso do uso do conceito de paradigma em economia. Apesar de Kuhn, num texto de 1974, ter dito que em seu livro a palavra paradigma teria sido usada em 22 sentidos diferentes, nenhum deles pode acolher a economia. (KUHN, 1996, p. 318). É que o paradigma "se halla en estrecha proximidad, tanto fisica como lógica, de la frase 'comunidad cientifica' (...) Un paradigma es lo que los miembros de una comunidad cientifica, yo sólo ellos, comparten." (KUHN, 1996, p. 318).

E, no caso da economia, o que se vai colocar é, decisivamente, a disputa, a controvérsia, a busca de explicar os mesmos fenômenos - a distribuição de renda, o desemprego, o crescimento econômico, a crise etc. - a partir de perspectivas distintas, não necessariamente convergentes algumas vezes, e radicalmente opostas quase sempre.

Assim, a possibilidade de aferição da cientificidade das teorias é sempre um exercício inverificável, sem validade universal. E aí, não se perca pela palavra - esta condição de inverificabilidade de universalidade é a própria expressão da natureza do objeto - a economia é uma disciplina política, é sempre economia política, na medida em que todas as suas categorias estão mergulhadas no mundo dos interesses, são realidades histórico-políticosociais, isto é, são realidades de poder. 
Trata-se aqui, centralmente, de, reconhecendo a existência de uma hegemonia teórica, isto é, a força de um certo programa de pesquisa em sua capacidade de disseminação e convencimento, contestar qualquer pretensão desta dominação em se impor como paradigma. Discutindo as razões do sucesso do modelo neowalrasiano, Screpanti e Zamagni (1993) dizem que há razões internas e externas que explicam tal sucesso. Do ponto de vista interno, dizem eles, a teoria neoclássica afirmou-se na medida em que a economia política clássica não ofereceu respostas convincentes aos problemas da teoria de valor e da distribuição da renda. Mas, mais importante, foram as razões externas: o fato da teoria neoclássica colocar-se, claramente, como admitiam Walras, Jevons, Wicksteed, Böhm-Bawerk e Pareto, como pensamento anti-socialista, antimarxista. (SCREPANTI \& ZAMAGNI, 1993, p. 152-3).

Não se tome esta constatação, a ausência de paradigmas em economia, como defesa de um relativismo amorfo, senão que o resultado da compreensão do caráter controverso, distante de toda a unanimidade, do objeto da economia. Daí que o racional, na consideração dos problemas epistemológicos em economia, tenha que rejeitar toda pretensão de exclusivismo, e reconhecer a centralidade do pluralismo.

\section{ECONOMIA MAINSTREAM: FALÁCIAS DO MÉTODO E LIMITES DA FORMALIZAÇÃO}

Em um extenso artigo publicado em 2000, Edward Lazear nos oferece uma defesa apologética da teoria econômica neoclássica que é exemplar da postura metodológica contemporânea do mainstream e de suas pretensões hegemônicas e excludentes. De acordo com Lazear o sucesso da abordagem neoclássica poderia ser atribuído ao seu rigor, que teria permitido fazer da economia não "apenas uma ciência social", mas uma "ciência genuina.” (2000, p. 99). A exemplo da física, a teoria econômica seguiria o método científico, "stating a formal refutable theory, testing the theory, and revising the theory based on the evidence." (p. 102). Sua influência crescente e a ampliação de suas áreas de aplicação decorreriam da existência de uma 
linguagem rigorosa "that allows complicated concepts to be written in relatively simple, abstract terms. The language permits economists to strip away complexity." (p. 99).

As seçôes seguintes discutem estas afirmações. Trata-se, primeiramente, de mostrar os limites de adesão ao que Lazear denomina de linguagem rigorosa, a formalização; em seguida, uma breve revisão do debate contemporâneo sobre a filosofia da ciência indicará o que há de equívoco e falacioso na postulação de um método científico universal e unívoco como a chave do sucesso da abordagem neoclássica em economia.

\subsection{A Formalização e seus Limites}

De acordo com Lazear, a habilidade de empregar uma linguagem abstrata diferenciaria a teoria econômica das ciências sociais. Ela teria permitido aos economistas focarem sua atenção em torno de três aspectos distintos, mas relacionados, que devem tomar parte em cada tentativa de explicar os fenômenos econômicos:

i) o pressuposto de que os agentes se comportam de modo racional ou maximizante, o que asseguraria a capacidade de realizar previsóes sobre este comportamento;

ii) a adesão a um conceito de equilíbrio como um aspecto central de qualquer tentativa de teorizar: "as in the physical sciences, equilibrium is a central concept in economics. (...) among social scientists, only economists insist on a physical-sciences-style equilibrium as part of the analysis" (p.101);

iii) o emprego de uma noção de eficiência como princípio orientador da análise, o resultado natural e esperado do modelo, que impede que o investigador, diante de um resultado inesperado (ineficiência), se satisfaça com uma "resposta parcial" ou "meia-verdade". (p.102).

Importa notar, de saída, que esta descrição dos postulados básicos da economia dá pouca atenção aos desenvolvimentos que, críticos a estes pressupostos, foram formulados por teóricos que em algum momento de suas 
carreiras localizavam-se no interior do próprio pensamento mainstream. Referimo-nos, por exemplo, aos questionamentos de pontos centrais da abordagem neoclássica como a informação gratuita e prontamente disseminada (ARROW, 1971; STIGLITZ, 1985); o comportamento maximizador dos agentes (SIMON, 1978; SEN, 1977); a racionalidade substantiva (SIMON, 1979); o mercado como locus de equilíbrio e de homogeneização (SCHUMPETER, 1984; GRILICHES, 1994); a inexistência de incerteza (KNIGHT, 1921) etc.

Toda vez que um destes temas é discutido de forma cuidadosa e aprofundada os resultados levam os autores a se afastarem das premissas básicas do pensamento mainstream, qualificando fortemente a teoria e, até mesmo, contribuindo para a elaboração de uma alternativa. ${ }^{6}$

Para nossos propósitos, entretanto, o artigo de Lazear tem a vantagem de expor sem rodeios ou hesitações as razões que, aos olhos de seus adeptos, explicam o sucesso da teoria neoclássica. Em sua franqueza, o argumento deixa expostos os muitos equívocos da autocompreensão teóricometodológica do mainstream.

Um exemplo disso é a tentativa de comparar o método da economia com o estilo analítico seguido pela física, resumidos, essencialmente, na centralidade do conceito de equilíbrio. Ignora-se, precisamente, que parte expressiva dos desenvolvimentos contemporâneos nas ciências da natureza deslocam a atenção para sistemas que, afastados do equilíbrio, são capazes

6 Por outro lado, a permanência da hegemonia da abordagem neoclássica sugere interrogaçóes interessantes sobre a capacidade do pensamento dominante de "absorver" todas as críticas ao "paradigma" sem maiores repercussões sobre o edifício teórico geral, sem qualquer reflexão sistemática sobre suas implicações. (NELSON \& WINTER, 1982). Isso não deve ser subestimado, pois as críticas mencionadas acima poderiam fundamentar uma mudança significativa na teoria econômica. ARROW (1995) chegou a sugerir esta perspectiva: "the foundations of economic analysis since 1870s have been rationality of individual behavior and the coordination of individual decisions through prices and markets. There has already been a steady erosion of these viewpoints, particularly with regard to the coordination function. Now the rationality of individual behavior is also coming under attack... What I foresee is a gradual systematization of dynamic adjustment patterns both at the level of individual behavior and at the level of interactions and transactions among economic agents. Indeed, the distinction between these levels may well be blurred and reclassified. In the course of this development, the very notion of what constitute an economic theory may well change." 
gerar organização espontânea, rupturas de simetria e evolução em direção a estruturas de complexidade e diversidade crescentes. (PRIGOGINE \& STENGERS, 1997).

De outro lado, não há qualquer hesitação da parte de Lazear em apontar o "teste do mercado" como indicador conclusivo, seja do bom estado da teoria econômica, seja da justeza de suas pretensões imperialistas sobre outras áreas de conhecimento: "economists generally believe in the market test. Economic imperialism can be judge to be successful only if it passes this test, which means that the analyses of the imperialists must influence others." (LAZEAR, 2000 , p. 104). Naturalmente, o autor não tem dificuldade de apontar disciplinas em que a influência da teoria econômica se faz sentir - política, demografia, sociologia, contabilidade etc. - e pode comemorar o fato de que, entre as ciências sociais, a economia "attracts most students, enjoys attention of policy-makers and journalists, and gains notice, both positive and negative, from other scientists." (p. 99). O que surpreende é o pressuposto irrefletido de que o sucesso de uma disciplina possa ser aferido pelo teste de mercado, a tentativa de representar a atividade científica como um mercado competitivo de idéias. Ainda que alguns estudos de economia da ciência tenham empregado a noção de um mercado de idéias, autores insuspeitos como Blaug (2001, p. 148-9) reconhecem que "the objections against taking the market-of-ideas as anything else other than a stimulating metaphor are so obvious as hardly to require discussion." Não se trata de negar uma dimensão econômica da atividade científica, mas de contestar que a mera transposição de argumentos neoclássicos sobre a eficiência de mercados competitivos seja adequada ou razoável para a compreensão do sucesso ou fracasso da busca de conhecimento. ${ }^{7}$

Mas a atitude dominante entre os economistas neoclássicos em relação a questões metodológicas pode ser caracterizada como de indiferença ou, por que não dizer, desprezo. Exemplo deste comportamento é a recomen-

7 Para uma crítica à noção de mercado de idéias de um ponto de vista simpático ao mainstream, ver WIBLE (1998). SENT (1999) discute as principais correntes contemporâneas da economia da ciência. 
dação de Frank Hahn (1992) às gerações mais novas de economistas no sentido de que "evitem discussões sobre o 'uso da matemática em economia' da mesma forma que se evita uma praga." Este desprezo pela metodologia contribuiu para que a formalização matemática fosse majoritariamente reconhecida como o único método válido em economia, conclusão que, além de falsa, incapacita esta disciplina para lidar adequadamente com a complexidade do seu objeto de estudo. Citando Chick,

\section{"[...] economics is a subject so complex and interwoven that the achievement of cogent knowledge by any single method is impossible; therefore there is scope and need for a variety of approaches.” (CHICK 1998, p. 1859)}

Antes de prosseguir, faz-se necessário definir o que se entende por formalização. De acordo com Backhouse (1998, p. 1848), é possível encontrar na literatura três definições diferentes para o termo: $i$ ) ele pode significar axiomatização, o que envolveria a redução do conhecimento a um conjunto de axiomas independentes e às proposições que possam ser derivadas dele por meio do uso de regras lógicas e bem definidas; ii) pode significar apenas o uso de técnicas matemáticas para expressar argumentos econômicos; ou, finalizando, iii) pode ser definido como o formalismo metodológico, entendido como o uso de um conjunto de métodos, amplamente aceitos, para a solução de certos tipos de problemas. Nesta última acepção, tais regras não exigiriam necessariamente o emprego da linguagem matemática. ${ }^{8}$

Seguindo Chick e Dow (2001, p. 705), o formalismo será aqui entendido como a "metodologia que requer que todos os argumentos sejam expressos, ou passiveis de serem expressos, na linguagem matemática", conceito que engloba as duas primeiras definiçóes apresentadas por Backhouse.

Entre os fatores usualmente citados na literatura como vantagens associadas ao uso do formalismo enquanto método de investigação em economia

8 WEINTRAUB (1998)também discute as várias interpretações possíveis para o conceito. 
estariam: a precisão, a transparência e a demonstração conclusiva. (BACKHOUSE, 1998). Woo (1986, p. 10), adicionaria a esta lista dois outros fatores: o fato da formalização deixar claro o que é assumido pela teoria e, assim, servir de salvaguarda contra verbalizações ad hoc e post hoc; e o fato da formalização permitir a determinação dos supostos mínimos necessários requeridos por uma teoria. Tais vantagens possibilitariam a utilização de um método de investigação científica caracterizado pela busca de leis e princípios invariantes e universais, tal como o adotado pela física pré-quântica.

Não se trata aqui de discutir todos os questionamentos que poderiam ser feitos a estas vantagens, ${ }^{9}$ mas de concentrar o argumento nos requisitos necessários para o emprego da formalização. Em primeiro lugar, a busca de leis invariantes e universais requer que o objeto de estudo apresente características especiais. Nas palavras de Chick e Dow (2001, p. 706),
"As Lawson (1997) has made us aware, to observe (or theorise about) event regularities requires that the system under observation (or the object of theory) approximate a closed system. Such system is defined by the extrinsic condition that it be isolated from outside influences and an intrinsic condition that the agents 'inside' the system behave in a consistent manner."

A utilização de sistemas fechados nas ciências naturais é amplamente difundida por meio da utilização de experimentos controlados. O sucesso obtido pelas referidas ciências disseminou o entendimento de que o modelo ideal de ciência deve centrar-se na busca de regularidades, obtidas sob condições ideais. Porém, não chega a ser controverso entre os economistas o fato de ser bastante difícil encontrar sistemas fechados em nosso campo de análise. O grande ponto de discórdia está nas implicações do fato de que as possibilidades de condução de experimentos controlados em nossa área

9 Ver, a propósito, WOO (1986), DOW (1997), LAWSON ( 1997) e CHICK \& DOW ( 2001). 
sejam bastante reduzidas ou, por que não dizer, nulas. Usualmente, a solução apresentada é avaliar a validade de uma teoria por meio de sua consistência interna. No entanto, como salientam:

"not only does the normal usage of the term 'consistency' refer to a particular and restrictive form of logic, but also the criterion of internal consistency does not ensure the relevance, or correspondence to reality, of the theory: avoidance of logical error does not prevent errors of application." (CHICK \& DOW, 2001, p. 707)

Além disto, se se considera o sistema social como um sistema aberto no qual os agentes econômicos aprendem e inovam e as instituições evoluem com o decorrer do tempo, torna-se extremamente problemático postular a transferência do conhecimento gerado em sistemas fechados ao contexto social.

Ademais, existe um problema inverso, qual seja, o da transposição de problemas do contexto social para o modelo teórico. Este último requer que o fato ou variável a ser analisada possam ser representados por meio da linguagem matemática. O ponto central aqui é: em que medida esta transposição não altera o significado da variável ou fato a ser analisado? $\mathrm{O}$ exemplo da racionalidade do agente econômico adotado pelo mainstream é clarificador. Para ser expressa axiomaticamente, uma série de fatores condicionantes da ação humana (dúvida, incerteza, euforia, ilusão e outros) foram excluídos da racionalidade do agente. É neste sentido que se diz que o uso da linguagem matemática não é neutro (DOW, 1996), vale dizer, que o uso de qualquer linguagem, seja ela matemática ou não, impõe a necessidade de adequar o que se quer expressar aos condicionantes desta linguagem. ${ }^{10}$

10 O que estamos salientado é que usualmente esta consideração não é compreendida pelos adeptos da formalização matemática. Além disto, a não neutralidade também se expressa na escolha das hipóteses de um modelo. Isto pode ser observado com a ajuda de um modelo IS-LM simples, expresso pelas seguintes equações $S(r, Y)=I^{*}, M^{*}=L(r, Y)$, onde * significa a exogeneidade da variável. A escolha de qual das duas variáveis será exógena definirá se o modelo é keynesiano (I exógeno) ou monetarista ( $\mathrm{M}$ exógeno). Como pode ser observado, a necessidade de escolher uma variável como exógena para que o sistema de equaçôes seja solucionado determinará o resultado obtido. 
Um outro aspecto a ser salientado refere-se à suposta precisão que a formalização matemática propicia. Esta alegada vantagem também possui seus problemas. A precisão seria decorrente tanto do uso de uma lógica coerente com os pressupostos adotados quanto, e principalmente, da necessidade de expressar variáveis com significado científico constante. No entanto, tal fato desconsidera que, tratando-se de um sistema aberto, é extremamente difícil encontrar variáveis que não mudem de significado com a evolução do sistema econômico. Exemplo claro disso é a definição de meios de pagamento. Enquanto no século XVII ela esteve referida apenas às moedas metálicas em circulação, nos dias de hoje a mesma variável também pode significar crédito. A evolução do sistema financeiro alterou o significado da variável em questão.

Todo este argumento não deve ser interpretado como uma negação dos possíveis benefícios que a formalização pode trazer, mas como um esforço para salientar que existem limitações para o seu uso. Do ponto de vista metodológico, por exemplo, é possível identificar regularidades no funcionamento do sistema econômico suficientemente estáveis para serem representadas matematicamente. No entanto, é preciso ter claro que o conhecimento assim gerado é transitório, tendo em vista o caráter aberto do objeto de estudo. A complexidade do mundo em que vivemos nos obriga a aceitar a pluralidade de métodos como um pré-requisito para o próprio desenvolvimento da ciência. ${ }^{11}$ Definir, como está em voga na economia, que o formalismo é o único método científico de investigação significa, na prática, restringir as possibilidades do desenvolvimento da reflexão sobre a economia.

11 Alguns autores (NELSON, 1995) descrevem a análise verbal enquanto uma metodologia descritiva anterior à formalização. Nosso ponto aqui é radicalmente contrário a esta posição. A pluralidade metodológica implica a não hierarquização de métodos. Todos são aceitos, tendo em vista o objeto de estudo. É a adequação ao objeto que determina a contribuição que um método pode ter (ou não) para a geração do conhecimento. 


\subsection{A Falácia do "Método Científico"}

Neste sentido, o que chama atenção no argumento de Lazear é a tentativa de assegurar as credenciais teóricas da economia pela recorrente afirmação de sua adesão ao "método científico", afirmação que faz supor a existência de um cânone metodológico sobre o qual não haja controvérsia. Entretanto, se há algo a aprender com a história da filosofia da ciência no século passado é que não existe tal consenso sobre os critérios que permitiriam incluir esta ou aquela disciplina no campo da ciência, ou sobre regras para a escolha entre teorias rivais. Em suas principais vertentes - o positivismo lógico e o popperianismo ou, mais genericamente, o indutivismo e o falsificacionismo -, o debate entre os filósofos da ciência na primeira metade do século XX revelou as limitações das diferentes tentativas de fornecer critérios universais para a escolha de teorias ou para a demarcação entre o conhecimento científico e outras formas de conhecimento. ${ }^{12}$

Os pressupostos destas formas convencionais de conceber a ciência remontam ao trabalho dos iluministas do século XVIII. Preocupados com a defesa das credenciais teóricas de suas próprias concepções, cientistas daquele período voltaram-se para a celebração das descobertas de seus predecessores de maneira a apresentar os seus próprios achados como o momento culminante de um lento e longo processo de avanço do conhecimento e, com ele, da civilização. Relatos deste tipo vinculavam a história da ciência a uma forma de narrativa em que os acontecimentos podiam ser enquadrados a partir do pressuposto de um progresso linear, um acúmulo contínuo dos conhecimentos humanos. ${ }^{13}$ Tal processo seria guiado pelo emprego do método científico, que permitiria afastar os erros e obstáculos ao avanço da nossa compreensão do mundo. Esta visão do progresso do entendimento esteve inicialmente apoiada num tipo peculiar de teoria do conhecimento, o empirismo, mas sobreviveu como um modelo para a elaboração da

12 CHALMERS (1993) faz uma síntese clara e ponderada dos principais impasses da filosofia da ciência no século XX.

13 Exemplos deste tipo de narrativa são a História da eletricidade, de Joseph Priest, e a História da astronomia, de Adam Smith, ambas escritas no século XVIII. 
história da ciência mesmo após o surgimento de outras abordagens epistemológicas. (GOLINSKI, 1998).

No entanto, como já notamos anteriormente, esta concepção sobre a trajetória histórica da ciência e as teses metodológicas a ela associadas passaram por uma cerrada crítica na segunda metade do último século. Os ataques partiram de diferentes disciplinas. Entre os historiadores, por exemplo, tais relatos foram acusados de compartilhar os pressupostos anacrônicos da "Whig history" e substituídos por uma preocupação com a compreensão do passado, que deslocou a ênfase das continuidades para as rupturas entre as concepções de conhecimento de cada período. De outro lado, um dos aspectos mais característicos da filosofia da ciência pós-popperiana foi a crítica à tese da existência de um método científico único ou universal. Para boa parte destes filósofos, a crítica se estendeu à própria tentativa de compreender o conhecimento a partir de regras de método, posição que encontrou uma formulação extremada, mas instigante, no anarquismo epistemológico de Feyerabend (1977). Finalmente, também os sociólogos da ciência constataram um divórcio entre a prática dos cientistas e sua suposta adesão à regras de método, que os levou à crítica da maneira convencional de conceber a evolução da ciência.

Este conjunto de reações, que encontrou uma primeira formulação abrangente na obra de Kuhn (1996), suscitou novas e diferentes maneiras de compreender a história e filosofia da ciência. Boa parte destas novas abordagens partilha da concepção do conhecimento científico como um produto humano, algo construído a partir de recursos materiais e culturais disponíveis em contextos específicos, e não como um desvelamento de uma ordem natural preestabelecida. (GOLINSKI, 1998, p. 6). A ciência é aí concebida como parte da praxis humana, ainda que não exista homogeneidade na maneira como cada autor compreende os nexos entre a ciência e o contexto social em que se desenvolve. O que importa frisar é que este tipo de abordagem abriu espaço para um amplo leque de estudos empíricos e interdisciplinares sobre a ciência. Trata-se não apenas de entender o funcionamento de instituições que permitem a existência da ciência, mas também de perguntar em que medida o modo de funcionamento destas instituições ou os valores que orientam a vida social podem moldar o 
conteúdo da ciência, por exemplo, seus objetivos ou o que pode ser aceito como conhecimento legítimo. (LACEY, 1998; GOLINSKI, 1998).

Estes desenvolvimentos, voltados inicialmente para a compreensão das ciências naturais e, especialmente, da física, também influenciaram o debate sobre a natureza da atividade científica entre os economistas. Nos últimos anos, difundiu-se a convicção entre os estudiosos da metodologia da economia de que a tentativa de formular regras universais que pudessem orientar a pesquisa teórica, regras que assegurassem as credenciais científicas da disciplina, revelou-se um retumbante fracasso:

"The current disarray within the philosophy of natural science has undermined the previous 'shelf of scientific philosophy' view of economic methodology. The process of weaning economic methodologists from the shelf of scientific philosophy - the view that methodologists simply take ideas off the shelf of scientific philosophy (what 'they' say good science is) - has been ongoing for many years, but it has accelerated as a result of the current malaise within the philosophy of natural science. (...) While there is a lot of controversy within contemporary science theory, there are a few points of relative consensus - antifoundationalism, naturalism, and the social nature of science - and these ideas have spilled over into economic methodology. (...) Gone is the empiricist-foundationalism that was once the generally accepted backdrop for all methodological discussion. (...) The economics profession, like all organizations of scientific practitioners, is a social organization and much (for some, all) of what is produced by this institution is a result of its sociality. (...).” (HANDS, 2001, p. 53-4; 54-5).

Lazear (2000), a exemplo da ampla maioria dos adeptos do mainstream em economia, parece ignorar estes problemas e segue atribuindo o "sucesso" da economia neoclássica a sua suposta adesão ao "método científico". Infelizmente, ele é bastante lacônico ao expor sua compreensão do que vem a ser este método. Somos informados apenas que a economia é científica porque "like the physical sciences, economics uses a methodology that produces 
refutable implications and tests these implications using solid statistical techniques.” (2000, p. 99)..$^{14}$

Para além do que possa haver de ingenuidade ou ignorância em afirmações como esta, importa notar que o fracasso das metodologias de inspiração positivista abriu espaço para o florescimento da discussão metodológica e a um número crescente de manifestações favoráveis a algum tipo de pluralismo metodológico. (CALDWELL, 1994; SALANTI \& SCREPANTI, 1997; BIANCHI, 1992). Esta posição, que renuncia a busca de um princípio metodológico único, consiste em afirmar a existência e a legitimidade de diferentes posições metodológicas no interior de cada disciplina científica:

"Methodological pluralism rejects any exclusivist
prescriptivism which seeks to establish one approach to
methodology as supreme or to give it a privileged position. This
rejection is in favour for a credentialist approach which
attempts to establish the specific bases on which particular
claims to knowledge rest, without affirming that one set of
credentials is a priori prescriptively superior to another."
(SAMUELS, 1998, p. 301).

Não se trata, portanto, de propor um "vale tudo" metodológico, mas de reconhecer a inexistência de um metacritério inequívoco para a escolha de teorias e compreender que, a exemplo do mundo econômico sobre o qual nos debruçamos, a empresa científica (e metodológica) é uma construção social, uma prática atravessada por interesses e valores diversos. É neste sentido que o exemplo de Erasmo de Roterdã ganha renovada e insuspeita atualidade, na medida em que uma consciência esclarecida sobre os limites da razão e da ciência há que ser solidária de uma prática científica apoiada na tolerância e no pluralismo.

14 Sua ênfase na necessidade de fazer abstrações, empregar pressupostos simplificadores e testar as implicaçốes das teorias (p. 102-3) sugere uma posiçã̃o semelhante àquela exposta por FRIEDMAN (1953). Com efeito, o ensaio sobre "A metodologia da economia positiva" consiste num dos mais influentes textos sobre o assunto e, provavelmente, "it is the only essay on methodology that a large number, perhaps the majority, of economists have ever read." (HAUSMAN, 1992b, p. 162). Apesar desta popularidade, o artigo de Friedman foi objeto de severa crítica ao longo dos 50 anos que nos separam de sua publicação, seja pelas falhas evidentes de sua argumentação, seja por não representar de maneira adequada a prática efetiva dos economistas. (BLAUG, 1980; HAUSMAN, 1992a). 


\section{REFERÊNCIAS BIBLIOGRÁFICAS}

ACKERMAN, Frank. Still dead after all these years: interpreting the failure of general equilibrium theory. Journal of Economic Methodology, v. 9, n. 2, p. 119-139, 2002.

ARROW, Kenneth. Economic welfare and the allocation of resources for invention. In: LAMBERTON, D. (ed.), Economics of information and knowledge. Harmondsworth: Penguin Books, 1971.

ARROW, Kenneth. Interview. Science, v. 267, p. 1617-1618, 17 March 1995.

BACKHOUSE, Roger. If mathematics is informal, then perhaps we should accept that economics must be informal too. Economic Journal, v. 108, n. 405 , p. 1848-1858. 1998.

BENSAÏD, Daniel. Marx, o intempestivo: grandezas e misérias de uma aventura crítica. Rio de Janeiro: Civilização Brasileira, 1999.

BIANCHI, Ana Maria. Muitos métodos é o método: a respeito do pluralismo em economia. Revista de Economia Politica, v. 12, n. 2, p. 135-142, 1992.

BORNHEIM, Gerd. Reflexões sobre o meio ambiente: tecnologia e política. In: STEIN, Ernildo e BONI, Luis de A. (orgs.), Dialética e liberdade. Porto Alegre/Petrópolis: Ed. UFRGS/Vozes, 1993.

BUCHANAN, James M.. Economics in the post-socialist century. The Economic Journal, v. 101, p. 15-21, 1991.

CALDWELL, Bruce. Beyond positivism: economic methodology in the twentieth century. Ed. Revista. London: Routledge, 1994.

CARROL, Lewis. Aventuras de Alice. Trad. port., Rio de Janeiro: Summus, 1977.

CASSIRER, Ernst. Ensaio sobre o homem. Trad. port., $3^{a}$ edição, São Paulo: Martins Fontes, 2001.

CHALMERS, Allan. O que é ciência afinal? Trad. port., São Paulo: Brasiliense, 1993.

CHICK, Victoria; DOW, Sheila. Formalism, logic and reality: a Keynesian analysis. Cambridge Journal of Economics, v. 25, n. 6, p. 705-721, 2001.

CHICK, Victoria. On knowing one's place: the role of formalism in economics. Economic Journal, v. 108, n. 451, p. 1859-1869, 1998.

DOW, Sheila. Keynes, the post Keynesians and methodology. 1996. Mimeografado.

. Mainstream economic methodology. Cambridge Journal of Economics, v. 21, p. 73-93, 1997. 
DRUMMOND, Arnaldo. Morte do mercado: ensaio sobre o agir econômico. 2002. Tese (Doutorado) Rio de Janeiro: UGF.

FERNANDEZ BUEY, Francisco. La ilusión del método. Barcelona: Crítica, 1991.

FEYERABEND, Paul K. Contra o método. Trad. port., Rio de Janeiro: Francisco Alves, 1977.

. Matando o tempo. Trad. port., São Paulo: Ed. da UNESP, 1996.

FOUCAULT, Michel. As palavras e as coisas. Trad. port., Lisboa: Martins Fontes / Portugália, s.d..

FRIEDMAN, Milton. The methodology of positive economics. In: Essays in positive economics. Chicago: University of Chicago Press, 1953.

GOLINSKI, Jan. Making natural knowledge: constructivism and the history of science. Cambridge: Cambridge University Press, 1998.

GRILICHES, Zvi. Productivity, R\&D, and the data constraint. American Economic Review, v. 84, n. 1, p. 1-23, 1994.

HAHN, Frank. Reflections. Royal Economic Society Newsletter, v. 77, 1992.

HANDS, D. Wade. Economic methodology is dead - long live to economic methodology: thirteen theses on the new economic methodology. Journal of Economic Methodology, v. 8, n. 1, p. 49-63, 2001.

HAUSMAN, Daniel. Why look under the hood? In: Essays on philosophy and economic methodology. Cambridge: Cambridge University Press, 1992a.

. The inexact and separate science of economics. Cambridge: Cambridge University Press, 1992b.

HAYEK, Friedrich. Economia e conhecimento. In: CARNEIRO, Ricardo (org.), Os clássicos da economia. Trad. port., v. 2, São Paulo: Ática, 1997.

HILL, Christopher. Origens intelectuais da Revolução Inglesa. Trad. port., São Paulo: Martins Fontes, 1992.

INGRAO, Bruna; ISRAEL, Giorgio. The invisible hand: economic equilibrium in the history of science. Trad. ingl., Cambridge: MIT Press, 1990.

KANT, Immanuel. Crítica da razão pura. Trad. port., Lisboa: Calouste Gulbenkian, 1985.

KANTOROWICZ, Ernst. Los dos corpos del rey. Trad. esp., Madrid: Alianza, 1985.

KOYRÉ, Alexander. Misticos, espirituales y alquimistas del siglo XVI alemanes. Trad. esp., Madrid: Akal, 1981. 
. Consideraçôes sobre Descartes. Trad. port., $3^{a}$ edição, Lisboa: Presença, 1986.

KUHN, Thomas. La tensión esencial. Trad. esp., $2^{\mathrm{a}}$ edição, México: F.C.E., 1996.

. The structure of scientific revolutions. $3^{\mathrm{a}} \mathrm{ed}$. Chicago: The University of Chicago Press, 1996.

LACEY, Hugh. Valores e atividade cientifica. São Paulo: Discurso Editorial, 1998.

LAWSON, Tony. Economics and reality. London: Routledge, 1997.

LAZEAR, Edward P. Economic imperialism. Quarterly Journal of Economics, v. 115, n. 1, p. 99-146, 2000.

LOUREIRO, Maria Rita (org.). 50 anos de ciência econômica no Brasil. Petrópolis: Vozes/FIPE, 1997.

LUBLINSKAYA, A. D. La crisis del siglo XVII y la sociedad del absolutismo. Trad. esp., $2^{a}$ edição. Barcelona: Crítica, 1983.

NELSON, Richard. Recent evolutionary theorizing about economic change. Journal of Economic Literature, v. 33, p. 48-90, 1995.

NELSON, Richard; WINTER, Sidney. An evolutionary theory of economic change. Cambridge: The Belknap Press of Harvard University Press, 1982.

PARSONS, Talcott. Ensayos de teoria sociológica. Trad. esp. Buenos Aires: Paidós, 1967.

PAULA, João Antonio de. A polifonia da modernidade. Kriterion, v. 38, n. 96, p. 55-69, 1997.

Walras no Journal des Économistes: 1860-65. Revista Brasileira de Economia, v. 56, n. 1, p. 121-146, 2002.

POPPER, Karl. Razão ou revolução?. In: Da revolução à liberalização: curso de introdução à ciência política. Trad. port., Brasília: Universidade de Brasília, s.d..

PRADO, Eleutério. A construção das diferenças entre os economistas. Revista da Sociedade Brasileira de Economia Politica, n. 9, 2001.

PRIGOGINE, Ilya; STENGERS, Isabelle. A nova aliança. Trad. port., $3^{\text {a }}$ ed. Brasília: Editora UnB, 1997.

PRZEWORSKI, Adam. Marxismo e escolha racional. Revista Brasileira de Ciências Sociais, v. 3, n. 6, 1988.

RICARDO, David. Princípios de economia politica e de tributação. Trad. port., $2^{a}$ edição. Lisboa: Calouste Gulbenkian, 1978. 
SALANTI, Andrea; SCREPANTI, Ernesto. Pluralism in economics: new perspectives in history and methodology. Cheltenham, UK: Edward Elgar, 1997.

SAMUELS, Warren. Methodological pluralism. In: DAVIS, John B. et alii, The handbook of economic methodology. Cheltenham: Edward Elgar, 1998.

SCHUMPETER, Joseph. Capitalismo, socialismo e democracia. Rio de Janeiro: Zahar,1984.

SCREPANTI, Ernesto; ZAMAGNI, Stefano. An outline of the history of economic thought. Trad. ingl., New York: Oxford University Press, 1993.

SEN, Amartya. Rational fools: a critique of the behavioural foundations of economic theory. In: SEN, A., Choice, welfare and measurement. Cambridge: Harvard University Press, 1977.

SENT, Esther-Mirjam. Economics of science: survey and suggestions. Journal of Economic Methodology, v. 6, n. 1, p. 95-124, 1999.

SHACKLE, G. L. S. Origens da economia contemporânea. Trad. port., São Paulo: Hucitec, 1991.

SIMON, Herbert. From substantive to procedural rationality. In: HAHN, F.; HOLLIS, M. (eds.), Philosophy and economic theory. London: Oxford University Press, 1979.

. Rationality as process and as product of thought. American Economic Review, v. 68, n. 2, p. 1-16, 1978.

STIGLITZ, Joseph E. Wither socialism? Cambridge, Mass: MIT, 1994.

WEINTRAUB, E. Axiomatisches missverständnis. Economic Journal, v. 108, n. 451 , p. 1837-1847. 1998.

WIBLE, James. The economics of science: methodology and epistemology as if economics really mattered. London: Routledge, 1998.

WOO, H. What's wrong with formalization in economics? An epistemological critique. Hong-Kong: Victoria Press, 1986.

YATES, Francis. Ensayos reunidos. Trad. esp., Mexico: F.C.E., 1991-1996.

\footnotetext{
Os autores agradecem os comentários de Ricardo Ruiz e de dois pareceristas anônimos a uma versão anterior do texto, isentando-os de responsabilidade pelos equívocos que porventura restarem.

(e-mail: doria@cedeplar.ufmg.br).

(e-mail: crocco@cedeplar.ufmg.br).

(e-mail: hugo@cedeplar.ufmg.br).

(e-mail: albuquer@cedeplar.ufmg.br).

(Recebido em setembro de 2002. Aceito para publicação em março de 2003).
} 